\title{
Effects of androgenic gland ablation on growth, sexual characters and spermatogenesis of the white shrimp, Litopenaeus vannamei (Decapoda: Penaeidae) males
}

\author{
Jorge Alfaro-Montoya ${ }^{1}$, Luís Hernández-Noguera ${ }^{1}$, Luís Vega-Alpízar ${ }^{1}$ \& Rodolfo Umaña-Castro ${ }^{2}$ \\ ${ }^{1}$ Estación de Biología Marina: Lic. Juan Bertoglia Richards, Escuela de Ciencias Biológicas, Universidad Nacional, \\ Puntarenas, Costa Rica \\ ${ }^{2}$ Laboratorio de Análisis Genómico, Escuela de Ciencias Biológicas, Universidad Nacional, Heredia, Costa Rica
}

Correspondence: J Alfaro-Montoya, Estación de Biología Marina: Lic. Juan Bertoglia Richards, Escuela de Ciencias Biológicas, Universidad Nacional, Puntarenas, Costa Rica. E-mail: jorge.alfaro.montoya@una.cr

\begin{abstract}
This research was implemented to study the effects of androgenic gland ablation in the white shrimp Litopenaeus vannamei to explore sex reversal potential as an alternative technology for monosex female mariculture based on the sex dimorphic growth of this species. The surgical procedure was applied to male postlarvae (PL) at different ages, after external sex differentiation, as well as in sex undifferentiated PL. Andrectomized males regenerated normal appendices including pereiopods and pleopods; however, body growth and relative size of regenerated petasmas and appendices masculinae were statistically inferior $(P<0.05)$ to control males. Spermatogenesis in andrectomized males was active, but a phenomenon of degradation of spermatids and reproductive tissues was detected. No sex reversal was accomplished regardless of PL age from sex undifferentiated stages (PL38) to sex differentiated stages (>PL55). The complete regeneration of sexual characters in andrectomized L. vannamei (Dendrobranchiata) is different from previous reports from Decapoda.
\end{abstract}

Keywords: Penaeidae, androgenic gland, Litopenaeus vannamei, sex reversal, shrimp

\section{Introduction}

Malacostracan crustaceans control sex differentiation by the androgenic gland $(\mathrm{AG})$ that releases the androgenic hormone. This insulin-like peptide has been identified in many crustaceans including amphipods, isopods and decapods (Ventura, Rosen \& Sagi 2011). In decapods, the insulin-like androgenic hormone (IAG) was found to regulate the masculinization of primary and secondary sexual characters (Ventura \& Sagi 2012).

In the family Penaeidae, the complete cDNA of IAGs, of the giant tiger prawn Penaeus monodon, the kuruma prawn Marsupenaeus japonicus and the Chinese shrimp Fenneropenaeus chinensis (Li, Li, Sun \& Xiang 2012) have been reported. The definitive demonstration of the AG structure and location by molecular probes has been done in P. monodon and F. chinensis (Banzai, Ishizaka, Asahina, Suitoh, Izumi \& Ohira 2011; Mareddy, Rosen, Thaggard, Manor, Kuballa, Aflalo, Sagi, Paterson \& Elizur 2011; Li et al. 2012).

In the most economically important penaeid species: the white shrimp Litopenaeus vannamei, the complete sequence of the IAG gene was recently reported (Vázquez-Islas, Garza-Torres, GuerreroTortolero \& Campos-Ramos 2014). The histology of the presumptive AG of Litopenaeus, including the southern shrimp Litopenaeus setiferus, the white shrimp Litopenaeus occidentalis, the blue shrimp Litopenaeus stylirostris and L. vannamei has been partially described (Campos-Ramos, Garza-Torres, Guerrero-Tortolero, Maeda-Martínez \& ObregónBarboza 2006; Garza-Torres, Campos-Ramos \& Maeda-Martínez 2009; Alfaro-Montoya \& Hernández 2012; Vázquez-Islas et al. 2014). These findings indicate that the $A G$ in Litopenaeus is associated to the terminal ampoule and stretched 
along the distal region of the descending vas deferens. The aim of this study is to evaluate the effects of the ablation of the presumptive AG (andrectomy) associated with the terminal ampoules of L. vannamei on growth, male sexual characters and spermatogenesis.

\section{Materials and methods}

Evaluation of L. vannamei dimorphic growth under pond and tank culture

The growth of 358 organisms cultured in a commercial semi-intensive earthen pond in Golfo de Nicoya, Costa Rica, was recorded monthly as body weight (BW) from postlarvae stage 12 (PL12) to PL108. Conventional aquaculture systems for L. vannamei harvest 3-month old animals; therefore, to evaluate dimorphic growth after harvesting age, a complementary tank culture experiment was implemented. Three groups of 160 animals each were harvested from commercial ponds at 21, 20 and $16 \mathrm{~g}$ BW for groups A: rainy season culture, B: rainy-dry season culture and C: dry-rainy season culture respectively. Each group was grown in a separated shaded external tank $\left(18 \mathrm{~m}^{2} ; 20 \mathrm{MT}\right.$; 9 shrimp per $\mathrm{m}^{2}$ ) at different periods of the year, allowing to compare performance under dry and rainy seasons. Culture time was different for each group depending on actual growth rate and it lasted until reaching at least $30 \mathrm{~g}$ for females at Estación de Biología Marina (EBM) in a flow-through system, using new water pretreated by high-pressure silica sand filtration and sedimentation. Animals were fed at 3\% BW of a dry commercial feed (Nicovita ${ }^{\circ}, 30 \%$ protein, Callao, Perú) supplemented with fresh frozen sardines (Opistonema sp.). Sex and BW was monitored monthly in the three groups by population samples of $n=20$ animals.

\section{Identification of the AG}

Bilaterally eyestalk ablated L. vannamei males $(n=3,30 \mathrm{~g} \mathrm{BW})$, were anaesthetized in cold water $\left(20^{\circ} \mathrm{C}\right) 8$ days post eyestalk ablation, and andrectomized by removing the coxas of their fifth pereiopods and the associated terminal ampoules. Samples of ampoules were fixed in Davidson's solution for $24 \mathrm{~h}$, dehydrated in ethyl alcohol, paraffin embedded and serially sectioned in crossorientation. Sections were stained in Hematoxylin and Eosin.

\section{Regeneration of pereiopods and male sexual characters}

Litopenaeus vannamei postlarvae were collected from commercial farms after 15 days of culture (PL 25-35), and transported to EBM for further culture in laboratory tanks (volume $=330 \mathrm{~L}$ ) until reaching the following PL stages. Three groups of males (MA: $n=25$, PL180, MB: $n=74$, PL70 and MC: $n=60$, PL5 5 to 107 , See Table 1) were andrectomized and monitored for regeneration of pereiopods, petasmas and appendices masculinae. Animals were mounted dorsally on Velcro straps or moulding clay under a dissecting stereo microscope. Petasma identification was done by removing the left first pleopod. Identified males were andrectomized. The coxas of the fifth walking legs were removed, as well as the terminal ampoules, the adjacent AGs, and vasa deferentia using fine tweezers. The appendix masculina associated with the left second pleopod was removed leaving the right pleopod intact as control. The regeneration of the ablated pleopod served as an additional tool to monitor the effects of AG ablation.

\section{Andrectomy of sex differentiated individuals}

Litopenaeus vannamei postlarvae from group B (previous experiment: PL70, $\quad \mathrm{BW}=4.36 \pm 1.44 \mathrm{~g}$ ) were further evaluated against a control group for body growth and re-development of sexual characters based on the following treatments:

Andrectomy (AN): As described above. First and second left pleopods were removed $(n=34)$.

Control (CO): removal of fifth walking legs damaging neither the coxa nor the ampoule-vas deferens. First and second left pleopods were also removed $(n=28)$.

Males from both treatments were maintained in the same tank (water volume $=330 \mathrm{~L}$ ) under a flow-through system, using new water pretreated by high-pressure silica sand filtration and sedimentation. Salinity was $32 \mathrm{ppt}$, temperature was maintained at $28^{\circ} \mathrm{C}$, and the photoperiod was 13:11 (L:D). Animals were fed daily ad libitum with Nicovita ${ }^{\odot}$ feed $(30 \%$ protein). After 4 months of culture, males from both treatments were inspected for the presence of ampoules/ spermatophores (CO) or absence of ampoules/ spermatophores (AN), and measured in terms of BW (g), total length (TL, mm; measured from 
Table 1 Evaluation of microsurgeries of fifth pereiopods on Litopenaeus vannamei males

\begin{tabular}{|c|c|c|c|}
\hline \multirow[b]{2}{*}{ Parameter } & \multicolumn{3}{|c|}{ Experimental groups } \\
\hline & MA & MB & MC \\
\hline Number of microsurgeries & 25 & 74 & 60 \\
\hline Culture time (months) & 8 & 4 & 3 \\
\hline Initial PL stage & 180 & 70 & $55-107$ \\
\hline Initial size (mm) & $97.8 \pm 6.4$ & $69.1 \pm 7.8$ & $36.6 \pm 3.6$ \\
\hline Initial weight $(\mathrm{g})$ & - & $4.36 \pm 1.44$ & $0.50 \pm 0.2$ \\
\hline Surgery mortality (\%) & 24 & 16 & 23 \\
\hline Number of final survivors & 14 & 47 & 12 \\
\hline Survival (\%) & 74 & 76 & 26 \\
\hline Final size $(\mathrm{mm})$ & $117.9 \pm 7.7$ & $110.5 \pm 7.3$ & $54.4 \pm 12.3$ \\
\hline Final weight (g) & $22.46 \pm 4.79$ & $18.19 \pm 3.52$ & - \\
\hline Regeneration of fifth pereiopods (\%) & 100 & 100 & 100 \\
\hline Regeneration of left petasma (\%) & 100 & 100 & 100 \\
\hline $\begin{array}{l}\text { Regeneration of left appendix } \\
\text { masculine (\%) }\end{array}$ & - & 100 & 100 \\
\hline
\end{tabular}

the eyestalk base to the tip of telson), regenerated petasma length (PEL) and petasma width (PEW, mm) and regenerated appendix masculina length (APL) and appendix masculina width (APW, mm).

\section{Ablation of sex undifferentiated postlarvae}

Litopenaeus vannamei postlarvae at PL30 were collected from a commercial farm, transported to EBM for further culture in laboratory tanks. Sex undifferentiated PL38 $\quad(\mathrm{BW}=0.052 \pm 0.015 \mathrm{~g})$ were selected for the following treatments:

Ablation (ABL): removal of fifth walking legs at PL38 as described above $(n=60)$.

Control (CO): Non treated group of PL38 $(n=92)$.

Both groups were cultured in separated tanks $(330 \mathrm{~L})$, since gross external signs of andrectomization are not evident at this young stage. Culture conditions were as indicated previously and the experiment lasted until reaching clear sex differentiation after PL82, and measured in terms of BW and TL.

\section{Spermatogenesis in andrectomized adult males}

Andrectomy was performed on mature males (6 months old, $n=4$ ). Males were dissected to remove testicular lobes for histological examination of spermatogenesis 12 months post andrectomy and were compared to histological sections from intact males. Tissues were fixed as described previously, paraffin embedded, sectioned and stained in Hematoxylin and Eosin.

\section{Statistics}

Body weights and lengths were analysed using $t$ test for independent samples, at $P<0.05$ (Ott 1984), using the program GNU PSPP version 0.8.1 (Boston, MA, USA). Male petasma and appendix masculina measurements were normalized as follows: relative petasma length, RPEL $=$ PEL/TL; relative petasma width, RPEW $=$ PEW/TL; relative appendix masculina length, RAPL = APL/TL; relative appendix masculina width, RAPW $=$ APW/TL. Normalized data were analysed by linear regression and $t$-test for independent samples, at $P<0.05$ (Ott 1984). The Levene statistic was applied to test for homogeneity of variance. Values are expressed as mean \pm SD. The Chi-square test of independence was used to compare male proportions in sex undifferentiated postlarvae (Ott 1984).

\section{Results}

\section{Dimorphic growth}

Litopenaeus vannamei cultured in tanks after reaching market size (of around 20 g BW) exhibit a clear sex related dimorphic growth, in terms of BW $(P<0.05)$. The growth of young shrimp in commercial earthen ponds from PL 12 to PL $108 \quad(\mathrm{BW}=12 \mathrm{~g})$ did not show any 
statistical difference between sexes $(P>0.05$; Fig. 1). Figure 1 summarizes the growth pattern followed by males and females in three farm-harvested populations, cultured during different seasons. Depending on environmental conditions, each group of animals grew at different rates, with group A: rainy season reaching $30 \mathrm{~g}$ for females in 3 months, group B: rainy-dry season reached $30 \mathrm{~g}$ after 5 months, and group C: dryrainy season reached $30 \mathrm{~g}$ after 10 months. On the other hand, males showed slower growth rates than females in each group, with statistically significant differences $(P<0.05)$.

\section{Identification of L. vannamei AG}

Serial sections of terminal ampoules (Fig. 2a), from bilaterally eyestalk ablated males, revealed the presence of a massive homogeneous group of cells organized in grape-like clusters at the distal section of the terminal ampoules (AG in Fig. 2b-d).

\section{Sex characteristics regeneration in males (PL55 and up)}

The experimental groups (Table 1) responded similar to the surgical procedure, reaching between 16 and 24\% mortality; however, final survival was inferior in the group of smallest males (C). Regardless of size, from 97.8, 69.1 and $36.6 \mathrm{~mm} \mathrm{TL}$, males from the three groups regenerated normal fifth pereiopods similar to the intact pereiopods; moreover, the first and second pleopods were also regenerated to apparently normal size as compared to unamputated pleopods, developing a normal petasma and appendix masculina. Development of gonopores was not studied in these experimental males.
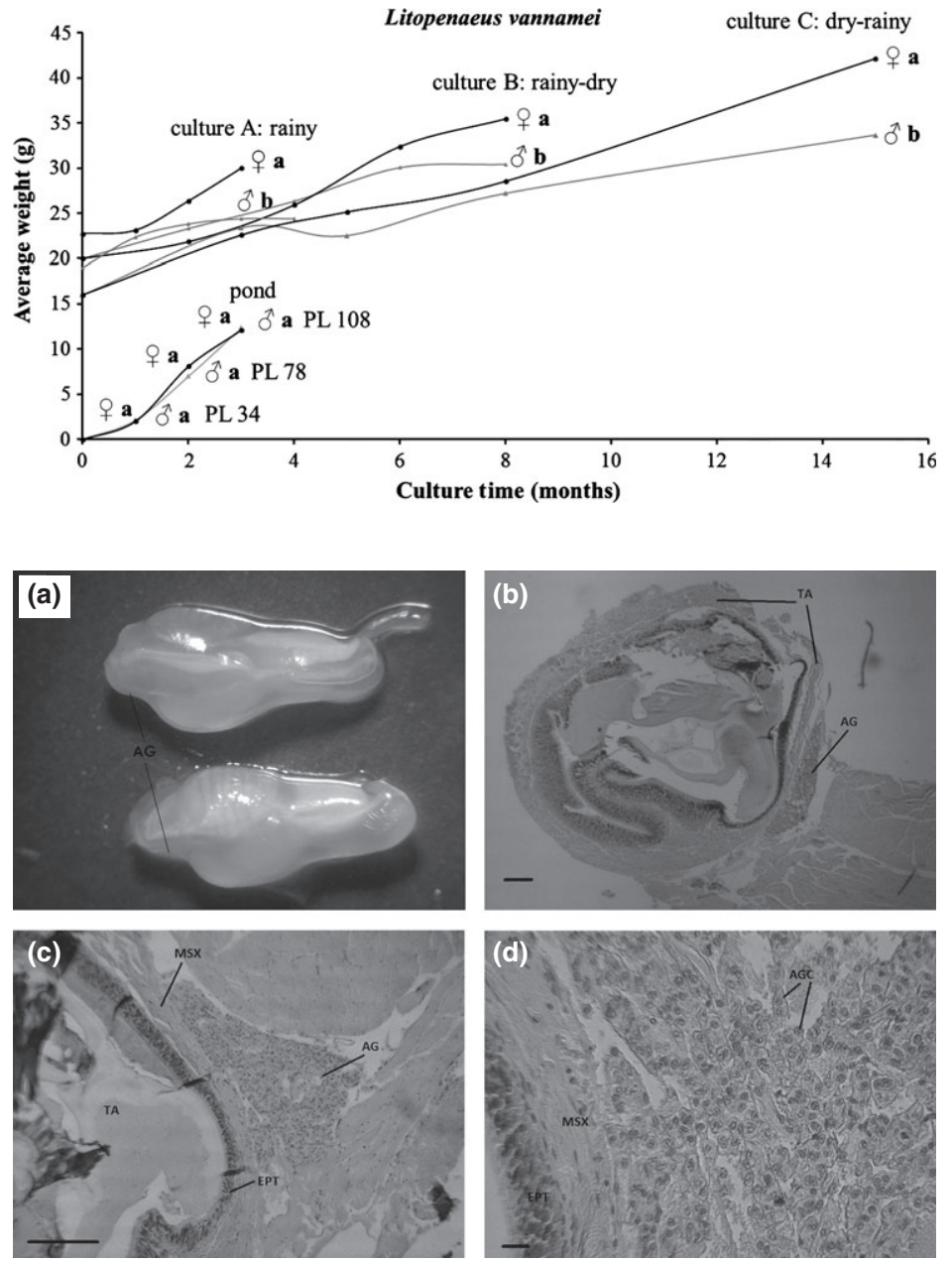

Figure 1 Average weight of male and female Litopenaeus vannamei grown under pond and tank culture at different seasons. Different letters indicate statistically significant differences $(P<0.05)$.

Figure 2 The presumptive AG of Litopenaeus vannamei. (a) Terminal ampoules, (b) cross-section of terminal ampoules at distal region, scale bar $=200 \mu \mathrm{m}$, (c) the AG mass, scale bar $=200 \mu \mathrm{m}$, (d) AG cells, scale bar $=20 \mu \mathrm{m}$. AG, androgenic gland; AGC, androgenic gland cells; TA, terminal ampoule; MSX, muscle layer; EPT, epithelial lining. 
Figure 3 Control (a-c) and andrectomized (b-d) males showing regenerated fifth pereiopods and left petasma of similar size to unamputated appendices. Andrectomized male does not present gonopores, terminal ampoules and spermatophores. SP, spermatophore; TA, terminal ampoule; PER5 REG, pereiopod fifth regenerated; NOR, normal; G, gonopore.
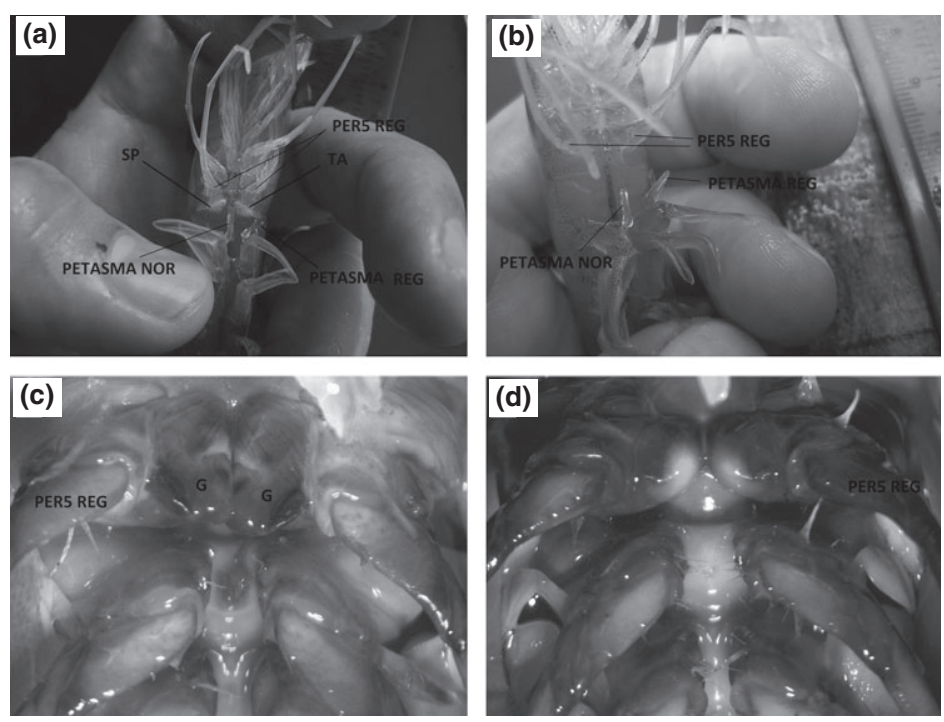

Andrectomy effects in sexually differentiated and undifferentiated individuals

Animals with fifth legs surgery at PL70 showed a complete regeneration of the petasma and the appendix masculina in control animals (Fig. 3a) as well as in andrectomized individuals (Fig. 3b). The only apparent difference between andrectomized and control individuals could be seen in the regeneration of the fifth pereiopods without gonopores and associated ampoules/spermatophores in the andrectomized (Fig 3d) compared to control (Fig 3c).

Andrectomized males after 4 months of culture showed significantly lower growth in weight (Fig. 4a) and length (Fig. 4b) than control males $(P<0.05)$. Complementarily, the dispersion pattern measured (Fig. 5a) separates the two groups of males based on their linear regression model and correlation coefficient. Andrectomized males presented a moderate positive correlation $(r=0.57)$ and the control group showed a weak negative correlation $(r=-0.21)$. Andrectomized males developed significantly smaller petasmas and appendices masculinae, in terms of normalized length and width (Fig. 5b, $P<0.05$ ). Regenerated pleopods developed into apparently normal size appendices as compared to unamputated appendices.

Spermatogenesis was observed in andrectomized adult males after 12 months of culture; testicular lobes show different cellular stages including spermatocytes and spermatids; the basic histology of testis from andrectomized males was compared
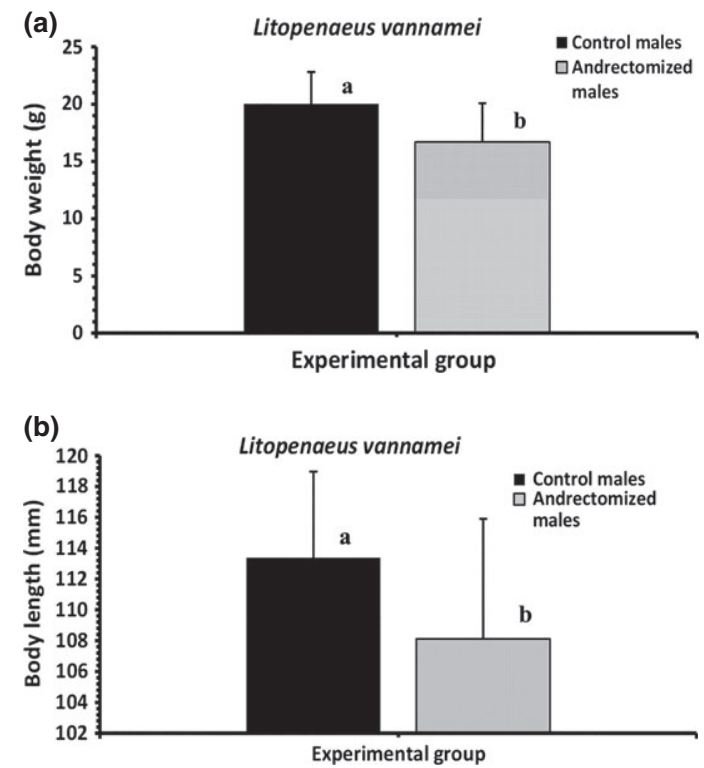

Figure 4 Body weight (a) and length (b) of andrectomized $(n=26)$ and control $(n=21)$ males, after 4 months of surgery at PL70. Treatments with different letters indicate statistically significant differences $(P<0.05)$.

against normal males cultured under the same experimental conditions. Histological alterations were evident in seminiferous tubules containing spermatids and in seminiferous ducts. The alterations that could be seen in the andrectomized animals can be described as follows: (1) seminiferous tubules with spermatids and degenerative masses 

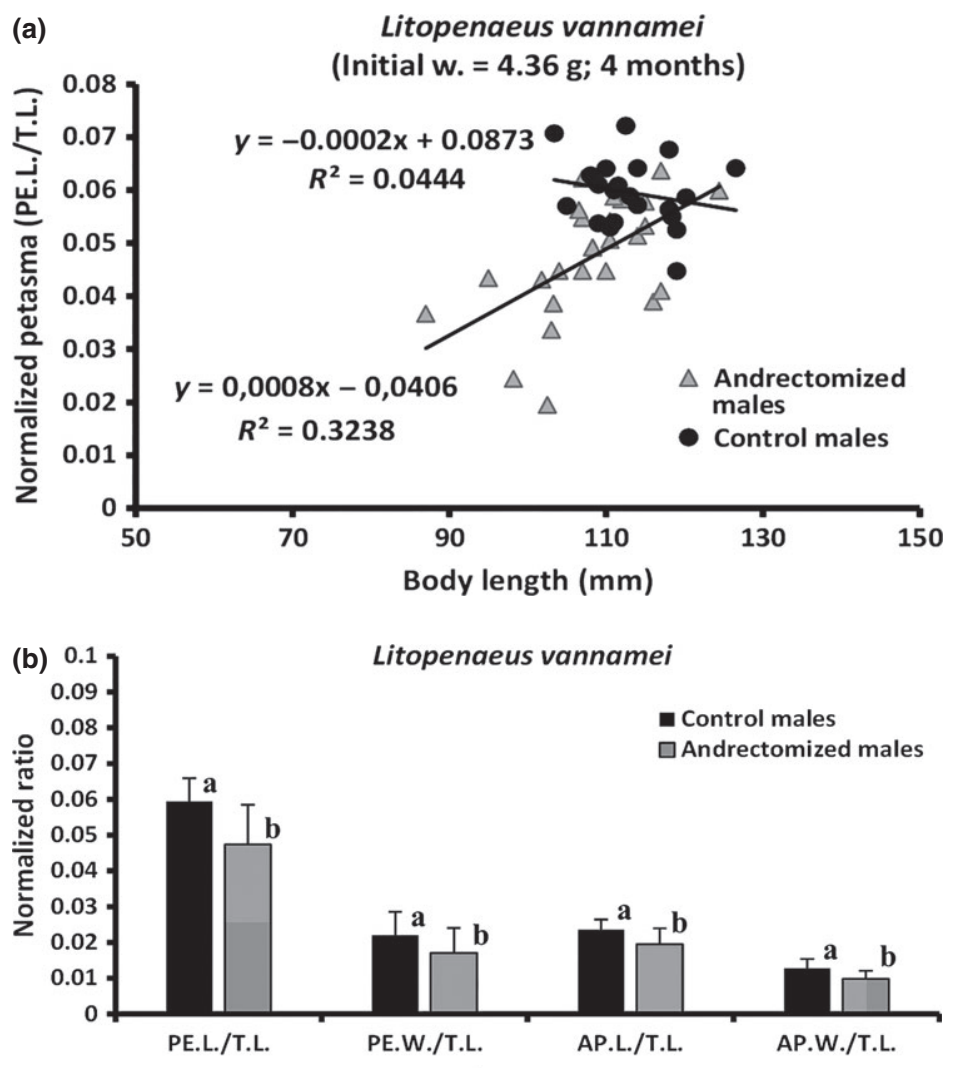

Figure 5 Scattergram and liner regression of body length and normalized petasma (PEL/TL) for andrectomized $(n=26)$ and control $(n=21)$ males (a), and relative growth of regenerated normalized petasmas in length and width (PEL/TL; PEW/TL) and appendices masculinae (APL/TL; APW/TL) from andrectomized and control males (b). Treatments with different letters indicate statistically significant differences $(P<0.05)$. of spermatids, (2) seminiferous ducts with spermatids and degenerative nodules and (3) degenerative ducts with white spherical nodules (Fig. 6).

In addition to these alterations, spermatids in seminiferous tubules from andrectomized males were in early stage (Fig. 6b), without acrosome formation as observed in normal males (Fig. 6a). This study was not intended for comparing testicular activity between andrectomized and normal males; however, our control males always showed tubules with early and mid spermatids; mid spermatids are characterized by the presence of acrosome structures.

The sex undifferentiated postlarvae group (PL38, $n=60$ ) had a surgery survival rate of $90 \%$. The group developed petasmas in 23 PL82, and 24 PL82 developed female first pleopods, given a male ratio $=48.9 \%$, statistically similar to the control group $(56.5 \% ; P>0.05$; Table 2$)$.

\section{Discussion}

Sex dimorphic growth under culture conditions in L. vannamei was not observed under $12 \mathrm{~g} \mathrm{BW}$; however, after around $20 \mathrm{~g}$ the growth between sexes diverges with time and it is dramatically and statistically superior for females after at least 3 months of culture, depending on the environment. Our findings are complementary to previous reports by evaluating the growth of sexes in adults (>30 g BW). The growth rate, in general, was better during the rainy season culture; the dry season is associated with low temperatures at night, reducing the growth of shrimp in commercial operations (Valverde-Moya \& Alfaro-Montoya 2013). The final differences in weight, in the three experimental groups, were in the range of 5.08.6 g. A similar pattern was reported for P. monodon (Gopal, Gopikrishna, Krishna, Jahageerdar, Rye, Hayes, Paulpandi, Kiran, Pillai, Ravichandran, Ponniah \& Kumar 2010); in this species the growth rate between sexes began to diverge in the range between 15 and $20 \mathrm{~g}$ BW. In L. vannamei, a previous study (Pérez-Rostro, Ramírez \& Ibarra 1999) indicated that after 160 days of culture, the growth rate was significantly different between females (18.09 g) and males (16.96 g). Complementarily, Pérez-Rostro and Ibarra (2003) observed that the weight for growth divergence between sexes is affected by the environment, and 
Figure 6 Histology of testicles from normal males (a) and andrectomized males (b-d) after 12 months of culture. (a) Normal seminiferous tubules (ST) with secondary spermatocytes (SPTC2) and mid spermatids (MSPMT), scale bar $=20 \mu \mathrm{m}, \quad$ (b) seminiferous tubules with degenerated spermatids (DEGSPMT), scale bar $=20 \mu \mathrm{m}$, (c) seminiferous duct (SD) with degenerated nodules (NOD) and vacuolated epithelium (EPT), scale bar $=20 \mu \mathrm{m}$, (d) Testicular lobule with a macroscopic nodule, scale bar $=100 \mu \mathrm{m}$. AC, acrosome, G, acrosomal granule.
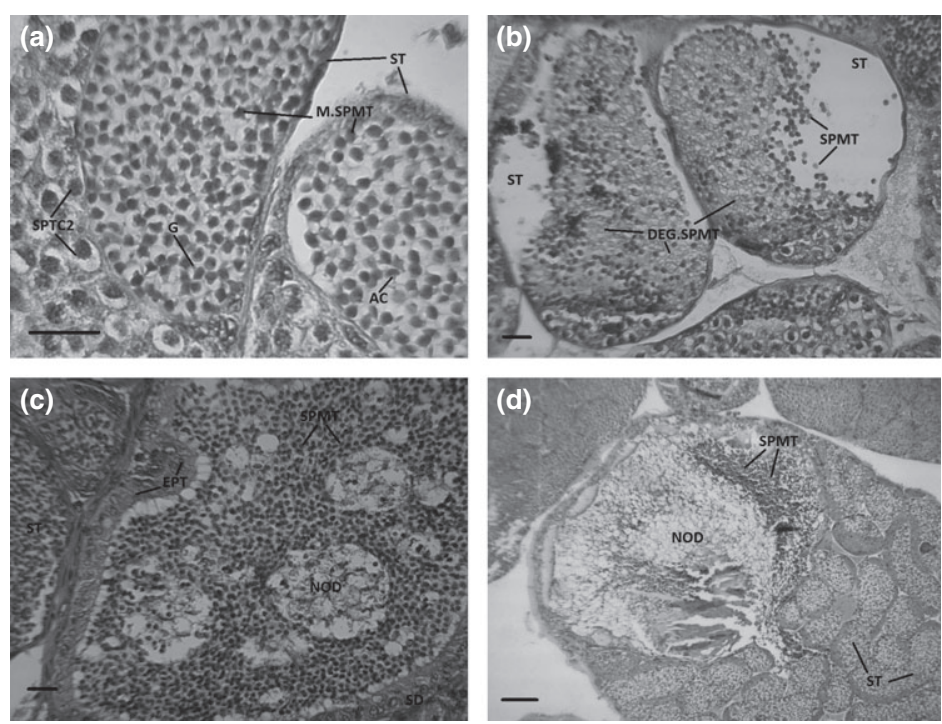

Table 2 Fifth pereiopods microsurgery of sex undifferentiated Litopenaeus vannamei postlarvae (PL38)

\begin{tabular}{llc}
\hline & \multicolumn{2}{l}{ Treatments } \\
\cline { 2 - 3 } Parameter & Surgery of fifth pereiopods & Control \\
\hline Initial PL stage & 38 & 38 \\
Number of replicates & 47 & 92 \\
Culture time (days) & 45 & 90 \\
Final PL stage & 82 & 127 \\
Female final size $(\mathrm{mm})^{\star}$ & $51.6 \pm 5.6^{\mathrm{a}}$ & $55.4 \pm 9.6^{\mathrm{a}}$ \\
Male final size $(\mathrm{mm})^{*}$ & $51.2 \pm 6.8^{\mathrm{a}}$ & $55.7 \pm 8.4^{\mathrm{a}}$ \\
Female final weight $(\mathrm{g})^{\star}$ & $1.88 \pm 0.49^{\mathrm{a}}$ & $2.37 \pm 1.25^{\mathrm{a}}$ \\
Male final weight $(\mathrm{g})^{\star}$ & $1.84 \pm 0.60^{\mathrm{a}}$ & $2.36 \pm 1.04^{\mathrm{a}}$ \\
Number of males & 23 & 52 \\
Number of females & 24 & 40 \\
Male ratio $(\%) \dagger$ & $48.9^{\mathrm{a}}$ & $56.5^{\mathrm{a}}$ \\
\hline
\end{tabular}

${ }^{*} t$-test for independent samples; sex mean values with the same letter, within treatment, indicate no statistically significant differences $(P>0.05)$.

$\dagger$ Chi-square: $\chi^{2}=0.7454, t$ value $(1)=3.8415, \alpha=0.05$, n.s.

Moss and Moss (2006) reported that sexual dimorphism for growth in L. vannamei is not the result of feeding behaviour, suggesting a physiological advantage.

Concerning the cellular structure of the AG, the histology of the cells associated with the distal region of terminal ampoules from L. vannamei, resembles previous descriptions made from Penaeidae (Mareddy et al. 2011; Li et al. 2012); the mass of cells is organized in grape-like clusters, as described by Li and Xiang (1997) for F. chinensis. The AG cells described in this study are similar to the findings reported by Vázquez-Islas et al. (2014) from the subterminal region of the ampoules.
Andrectomized L. vannamei males regenerated normal fifth pereiopods without gonopores and developed shorter and thinner petasmas and appendices masculinae in amputated pleopods, as compared to control males, during the 4 months of culture, following surgery. Amputated and normal appendices were apparently similar in size. A similar pattern in petasma growth was observed by Li and Xiang (1997) for F. chinensis, without statistical confirmation. In the Indian prawn Fenneropenaeus indicus, amputated petasmas and appendices masculinae did not regenerate in andrectomized adult males (Mohamed \& Diwan 1991). In the giant freshwater prawn Macrobrachium rosenbergii males, andrectomy caused appendices masculinae 
of unamputated second pleopods to grow slower than normal, and regenerated pleopods did not develop appendices masculinae at all (Nagamine, Knight, Maggenti \& Paxman 1980). In the Australian red claw crayfish Cherax quadricarinatus, the fifth pereiopods of andrectomized males did not regenerate (Tropea, Hermida \& López-Greco 2011). Therefore, it seems that appendix and sexual characters regeneration in Pleocyemata and Dendrobranchiata is a complex phenomenon.

Growth of andrectomized males was lower than control males. Males from both treatments were cultured in the same tank, and the lower growth of andrectomized males is a novel observation in penaeid shrimps. This is similar to other decapod crustaceans in which the AG was suggested as a growth promoting agent as studied in AG implantation experiments in females (Manor, Aflalo, Segall, Weil, Azulay, Ventura \& Sagi 2004) and AG ablation in males (Sagi, Cohen \& Milner 1990). In M. rosenbergii, a reduction in growth following AG ablation was measured (Sagi et al. 1990), and silencing of the Mr-IAG gene by dsRNA causes the reduction in growth rate in males (Ventura, Manor, Aflalo, Weil, Raviv, Glazer \& Sagi 2009), suggesting that IAGs can enhance growth in crustaceans. Contrary to the above, Li et al. (2012) suggested that in penaeids such as P. monodon, since females exhibit a higher growth rate, IAG is not necessary for enhancing growth because it only exists in male-specific AG (Mareddy et al. 2011). In C. quadricarinatus, AG implantation in females increased their growth rate and became similar to that of males (Manor et al. 2004); however, no growth effect was associated with AG ablation in males (Tropea et al. 2011). Our findings indicate that the AG of $L$. vannamei may have an enhancement effect on male somatic growth at early ages.

Spermatogenesis was altered in andrectomized males as indicated by histological evidence. In normal males, spermatogenesis advances in seminiferous tubules to mid spermatid stage; advanced spermatids and spermatozoa are only observed in vasa deferentia (Alfaro-Montoya 2013). These alterations are associated with the integrity of spermatids and the normal structure of seminiferous ducts, particularly with the integrity of the epithelial layer, generating reproductive tissue abnormalities that can reach macroscopic dimensions characterized by white spherical nodules (Fig. 6c,d).
The alterations observed in testicles of andrectomized males were associated with seminiferous tubules and ducts, containing spermatids at early stage. These alterations suggest that spermatid maturation is stopped and cellular degradation is activated, starting in seminiferous tubules, with the formation of degraded nodules that can reach macroscopical dimension affecting tubules and ducts. Such alterations could be the result of having an underdeveloped reproductive system, incapable of completing spermatogenesis at vas deferens nor assembling spermatophores in terminal ampoules (Alfaro-Montoya 2010). Andrectomy could also affect the normal process of spermatogenesis, interrupting spermatid maturation, as suggested for other crustaceans, including $M$. rosenbergii (Nagamine et al. 1980) and F. indicus (Mohamed \& Diwan 1991). The degradation of seminiferous tubules and ducts may indicate that the AG might also play a role in maintaining the reproductive system throughout the animal's life, as suggested by Tropea et al. (2011) for C. quadricarinatus.

Andrectomy of sexually undifferentiated individuals (PL38) did not induce any measurable shift in sex ratio, suggesting that sex reversal in L. vannamei requires AG ablation or molecular intervention in its specific hormone/s at younger stages than PL38, or that the removal of the AG via this method was incomplete. According to Garza-Torres et al. (2009) external sex differentiation occurs around PL32; however, the genital organs differentiate sooner (PL16). A complementary study by Campos-Ramos et al. (2006) indicates that external differentiation in L. vannamei begins around PL50, independently of size between 0.2 and $0.6 \mathrm{~g}$.

This contribution demonstrated, for the first time, in an open thelyca shrimp: L. vannamei, that andrectomy causes a complete regeneration of appendices, including pereiopods and pleopods. Andrectomized males showed a lower growth rate and smaller petasmas and appendices masculinae as compared to control males. Spermatogenesis in andrectomized males is active with degradation of spermatids and reproductive tissues. No sex reversal was achieved regardless of postlarvae stage starting at PL38.

\section{Acknowledgments}

This contribution was supported by Consejo Nacional de Rectores (CONARE), Costa Rica. The 
authors wish to thank shrimp farmers from Golfo de Nicoya, José Valverde Moya and Jorge Paternina Mancilla (Laboratorio de Larvicultura Activos de Crustáceos del Pacífico S.A.) for their cooperation in shrimp postlarvae supply. To Prof. Amir Sagi and Dr. Eliahu Aflalo, from Ben Gurion University of the Negev, Israel, for their cooperation and valuable comments.

\section{References}

Alfaro-Montoya J. (2010) The reproductive conditions of male shrimps, genus Penaeus, sub-genus Litopenaeus (open thelyca penaeoid shrimps): a review. Aquaculture 300, 1-9.

Alfaro-Montoya J. (2013) Descripción histológica de la oogénesis y espermatogénesis del camarón de cultivo, Litopenaeus vannamei. Revista de Biología Marina $y$ Oceanografía 48, 335-344.

Alfaro-Montoya J. \& Hernández L. (2012) The histological structure of the androgenic gland and cellular cord of the male reproductive system of adult Litopenaeus and Rimapenaeus byrdi. Journal of Crustacean Biology 32, 351-357.

Banzai K., Ishizaka N., Asahina K., Suitoh K., Izumi S. \& Ohira T. (2011) Molecular cloning of a cDNA encoding insulin-like androgenic gland factor from the kuruma prawn Marsupenaeus japonicus and analysis of its expression. Fisheries Science 77, 329-335.

Campos-Ramos R., Garza-Torres R., Guerrero-Tortolero D.A., Maeda-Martínez A.M. \& Obregón-Barboza H. (2006) Environmental sex determination, external sex differentiation, and structure of the androgenic gland in the Pacific white shrimp Litopenaeus vannamei (Boone). Aquaculture Research 37, 1583-1593.

Garza-Torres R., Campos-Ramos R. \& Maeda-Martínez A.M. (2009) Organogenesis and subsequent development of the genital organs in female and male Pacific white shrimp Penaeus (Litopenaeus) vannamei. Aquaculture 296, 136-142.

Gopal C., Gopikrishna G., Krishna G., Jahageerdar S.S., Rye M., Hayes B.J., Paulpandi S., Kiran R.P., Pillai S.M., Ravichandran P., Ponniah A.G. \& Kumar D. (2010) Weight and time of onset of female-superior sexual dimorphism in pond reared Penaeus monodon. Aquaculture 300, 237-239.

Li F. \& Xiang J. (1997) Preliminary studies on form, structure and function of androgenic gland in Penaeus chinensis. Chinese Science Bulletin 42, 499-503.

Li S., Li F., Sun Z. \& Xiang J. (2012) Two spliced variants of insulin-like androgenic gland hormone gene in the Chinese shrimp, Fenneropenaeus chinensis. General and Comparative Endocrinology 177, 246-255.

Manor R., Aflalo E.D., Segall C., Weil S., Azulay D., Ventura T. \& Sagi A. (2004) Androgenic gland implanta- tion promotes growth and inhibits vitellogenesis in Cherax quadricarinatus females held in individual compartments. Journal of Invertebrate Reproduction and Development 45, 151-159.

Mareddy V.R., Rosen O., Thaggard H.B., Manor R., Kuballa A.V., Aflalo E.D., Sagi A., Paterson B. \& Elizur A. (2011) Isolation and characterization of the complete cDNA sequence encoding a putative insulin-like peptide from the androgenic gland of Penaeus monodon. Aquaculture 318, 364-370.

Mohamed K.S. \& Diwan A.D. (1991) Effect of androgenic gland ablation on sexual characters of the male Indian white prawn Penaeus indicus H. Milne Edwards. Indian Journal of Experimental Biology 29, 478-480.

Moss D.R. \& Moss S.M. (2006) Effects of gender and size on feed acquisition in the Pacific white shrimp Litopenaeus vannamei. Journal of the World Aquaculture Society 37, 161-167.

Nagamine C., Knight A.W., Maggenti A. \& Paxman G. (1980) Effects of androgenic gland ablation on male primary and secondary sexual characteristics in the Malaysian prawn, Macrobrachium rosenbergii (de Man) (Decapoda, Palaemonidae), with first evidence of induced feminization in a nonhermaphroditic decapod. General and Comparative Endocrinology 41, 423-441.

Ott L. (1984) An Introduction to Statistical Methods and Data Analysis. Duxbury Press, Boston, MA, USA, 775pp.

Pérez-Rostro C.I. \& Ibarra A.M. (2003) Heritabilities and genetic correlations of size traits at harvest size in sexually dimorphic Pacific white shrimp (Litopenaeus vannamei) grown in two environments. Aquaculture Research 34, 1079-1085.

Pérez-Rostro C.I., Ramírez J.L. \& Ibarra A.M. (1999) Maternal and cage effects on genetic parameter estimation for Pacific white shrimp Penaeus vannamei Boone. Aquaculture Research 30, 681-693.

Sagi A., Cohen D. \& Milner Y. (1990) Effect of androgenic gland ablation on morphotypic differentiation and sexual characteristics of male freshwater prawns, Macrobrachium rosenbergii. General and Comparative Endocrinology 77, 15-22.

Tropea C., Hermida G.N. \& López-Greco S.L. (2011) Effects of androgenic gland ablation on growth and reproductive parameters of Cherax quadricarinatus males (Parastacidae, Decapoda). General and Comparative Endocrinology 174, 211-218.

Valverde-Moya J.A. \& Alfaro-Montoya J. (2013) La experiencia del cultivo comercial de camarones marinos en estanques de producción en Costa Rica. Revista Ciencias Marinas y Costeras 5, 87-105.

Vázquez-Islas G., Garza-Torres R., Guerrero-Tortolero D. \& Campos-Ramos R. (2014) Histology of the androgenic gland and expression of the insulin-like androgenic gland hormone precursor gene in the genital organ of pacific white shrimp Litopenaeus vannamei. Journal of Crustacean Biology 34, 293-299. 
Ventura T. \& Sagi A. (2012) The insulin-like androgenic gland hormone in crustaceans: from a single gene silencing to a wide array of sexual manipulation-based biotechnologies. Biotechnology Advances 30, 15431550 .

Ventura T., Manor R., Aflalo E.D., Weil S., Raviv S., Glazer L. \& Sagi A. (2009) Temporal silencing of an androgenic gland-specific insulin-like gene affecting phenotypical gender differences and spermatogenesis. Endocrinology 150, 1278-1286.

Ventura T., Rosen O. \& Sagi A. (2011) From the discovery of the crustacean androgenic gland to the insulinlike hormone in six decades. General and Comparative Endocrinology 173, 381-388. 